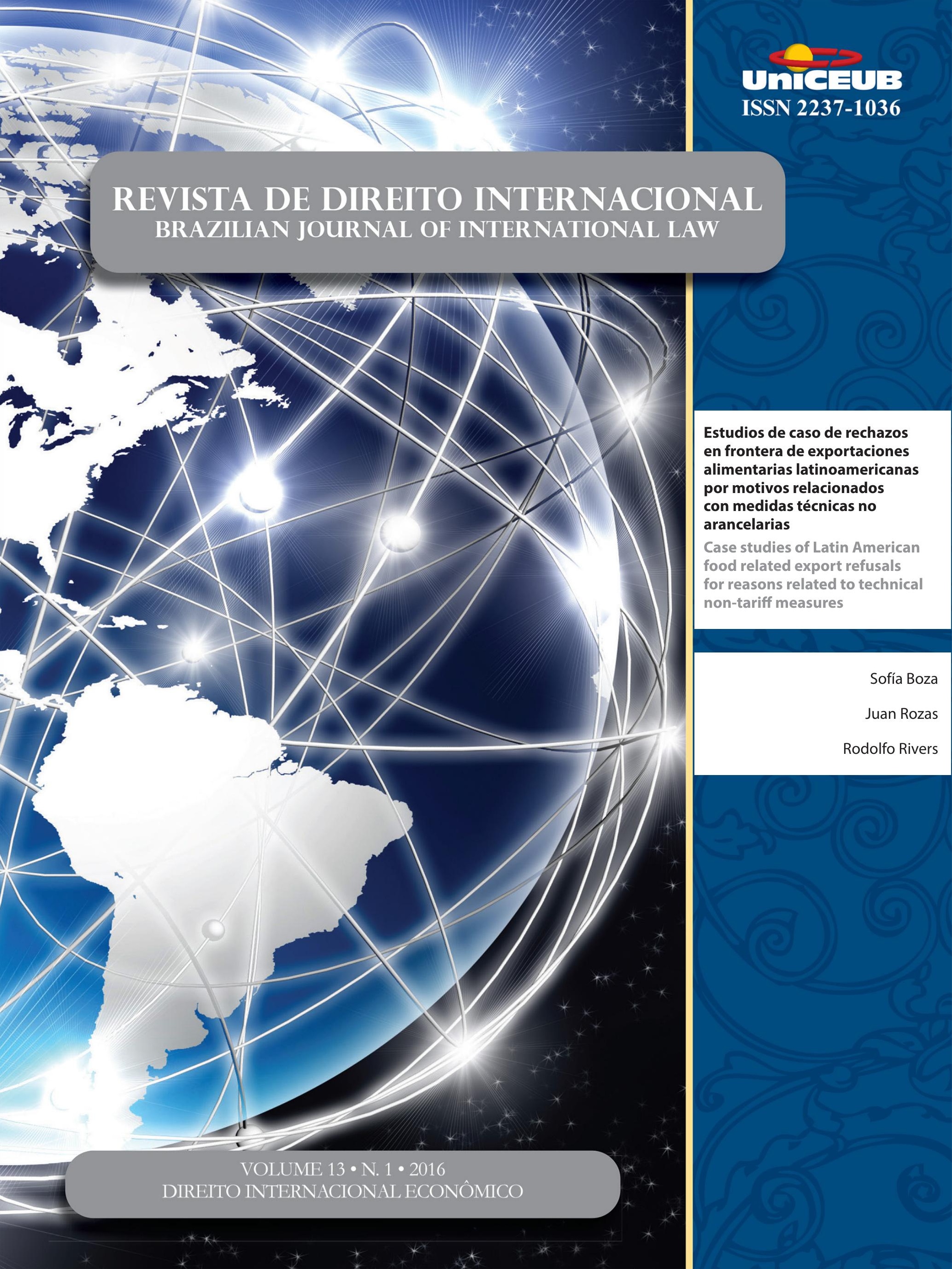




\section{Sumário}

Dossiê Temático: Direito Internacional Econômico.........................................................1

EDITORIAL:

Resultados da III Conferência Bienal da Red DEI ................................................. 3

Michelle Ratton Sanchez-Badin (em nome da Diretoria da Red DEI), Fabio Costa Morosini e Lucas da Silva Tasquetto (em nome dos organizadores da III Conferência da Red DEI)

Direito Internacional Econômico no Brasil: QUem Somos E o QUE faZemos? EvidênCIas EMPÍRICAS DE 1994 A 2014

Michelle Ratton Sanchez Badin, Fabio Costa Morosini e Inaê Siqueira de Oliveira

UM ESPAÇO PARA PENSAR EM ALTERNATIVAS? A ACADEMIA LATINO-AMERICANA DE DIREITO INTERNACIONAL ECONÔMICO FRENTE À ORDEM ECONÔMICA GLOBAL

Nicolás Marcelo Perrone

Grupo de alto Nível Brasil - Urugua (GAN): um Novo paradigma para a INTEgraÇão PRODUTIVA NO MERCOSUL

Alebe Linhares Mesquita e Vivian Daniele Rocha Gabriel

O COMÉRCIO de SERVIÇOS ENTRE Brasil E URUGUAI: LiberalizaÇÃo, DESAFIOS E PERSPECTIVAS DO SETOR DE TECNOLOGIA DA INFORMAÇÃO E COMUNICAÇÃO (TIC) E SOFTWARES

Vivian Daniele Rocha Gabriel e Alebe Linhares Mesquita

Core Labor Standards No Regime de PREFERÊNCIAS TARIFÁrias No MERCOSUL: A NeCESSIDADE DE HUMANIZAÇÃO DO COMÉRCIO INTERNACIONAL

Martinho Martins Botelho e Marco Antônio César Villatore

ACordo TRIMS: FleXibilizaÇão ou Não? Política de CONTEÚdo loCal, PROCESSO PROdUTIVO BÁSICO (PPB) E OS DESAFIOS PARA A INDÚSTRIA BRASILEIRA E A INTEGRAÇÃo LATINO-AMERICANA 100

Natália Figueiredo 
ESTUDIOS DE CASO DE RECHAZOS EN FRONTERA DE EXPORTACIONES ALIMENTARIAS LATINOAMERICANAS POR MOTIVOS RELACIONADOS CON MEDIDAS TÉCNICAS NO ARANCELARIAS.

Sofía Boza, Juan Rozas e Rodolfo Rivers

América do Sul em face dos tratados bilaterais de inVESTimento: RUMO aO RETORNo do EsTADO NA SOLUÇão DE CONTROvÉRSIAS? 133 Magdalena Bas

FutURo DE LOS SISTEMAS NACIONALES DE CIENCIA TECNOLOGÍA E INNOVACIÓN EN LA AGENDA ECONÓMICA DE AMÉRICA LATINA: DEFINIENDO CAMBIOS REGULATORIOS O PROTEGIENDO INVERSIONES 146

Rodrigo Corredor

EL PAPEL DE LAS INSTITUCIONES DE CONTROL FINANCIERO SOBRE LOS DERECHOS HUMANOS EN EL CONTEXTO LATINOAMERICANO 157 Jose Miguel Camacho Castro

CONVERGENCIA REgUlATORIA EN LA ALIANZA DEL PACÍFICO: UN CAPÍTULO INCONCLUSO 170 Rodrigo Polanco Lazo

O CONSTITUCIONALISMO E A COMUNITARIZAÇÃO NO DIREITO INTERNACIONAL: POSSIBILIDADES PARA O COMÉRCIO INTERNACIONAL?

Camilla Capucio

ESCASSEZ HÍDRICA E DIREITO INTERNACIONAL ECONÔMICO: O BRASIL COMO PROTAGONISTA NA TRANSFERÊNCIA DE ÁGUA PARA REGIÕES ÁRIDAS

Douglas de Castro

A Segurança energética como base para maior integração na América Do Sul: à espera DE UM TRATADO MULTILATERAL

Matheus Bassani

Outros Artigos. 246

As PRÁtICAS RESTRITIVAS DA CONCORRÊNCIA NO MERCADO DE CONTRATAÇÃo PÚBLICA EUROPEU .. 248 Alice Rocha da Silva e Ruth M. P. Santos 
Do TRANSNACIONAL PARA O NACIONAL: IOSCO, O MERCADO DE VALORES MOBILIÁRIOS BRASILEIRO E ACCOUNTABILITY

Salem Nasser, Nora Rachman e Viviane Muller Prado

MigRaÇÃo de TRABALHADORES INTELECTUAIS BRASILEIROS PARA O MERCADO INTERNACIONAL: IDENTIFICAÇÃO DE ATOS DE ALICIAMENTO DE EMPREGADOS E MECANISMOS LEGAIS PARA IMPEDIR A APROPRIAÇÃo TECNOLÓGICA E CONCORRÊNCIA DESLEAL ..........................................285 José Carlos Vaz e Dias e João Marcelo Sant'Anna da Costa

THE EASIER WAY TO HAVE "BETTER LAW"? THE MOST-SIGNIFICANT-RELATIONSHIP DOCTRINE AS THE FALLBACK CONFLICT-OF-LAW RULE IN THE PEOPLE'S REPUBLIC OF CHINA

Chi Chung

REFLEXOS JURÍDiCOS DA GOVERNANÇA GLOBAL SUBNACIONAL: A PARADIPLOMACIA E O DIREITO INTERNACIONAL: DESAFIO OU ACOMODAÇÃO 320

Valéria Cristina Farias e Fernando Rei

Matrizes Políticas da JUSTiÇA PENAL INTERNACIONAL. 341 Francisco Rezek

RESPONSABILIDAD INTERNACIONAL DEL ESTADO FRENTE A LUCHA CONTRA LA DISCRIMINACIÓN RACIAL Y ÉTNICA EN ESPAÑA. 348

Edilney Tomé da Mata e Eduardo Biacchi Gomes Correio

The Peace Process in Sierra Leone: an analysis on marriages between culture and CRIME

Gustavo Bussmann Ferreira

Funcionalização e expansão do Direito Penal: o Direito Penal negocial ...............376 Antonio Henrique Graciano Suxberger e Dermeval Farias Gomes Filho

Proteção Internacional do Consumidor e Cooperação Interjurisdicional .396 Héctor Valverde Santana e Sophia Martini Vial

The land rights of indigenous and traditional peoples in Brazil and Australia.... 418 Márcia Dieguez Leuzinger e Kylie Lyngard 
The reception of European ideas in Latin America: the issue of the German sources in Tobias Barreto, A Prominent nineteenth CENTURy BraZilian legal scholar........439 Arnaldo Sampaio de Moraes Godoy

Normas Editoriais ..................................................................................... 461 


\title{
Estudios de caso de rechazos en frontera de exportaciones alimentarias latinoamericanas por motivos relacionados con medidas técnicas no arancelarias*
}

\author{
Case studies of Latin American food related \\ export refusals for reasons related to \\ technical non-tariff measures
}

\author{
Sofía Boza** \\ Juan Rozas*** \\ Rodolfo Rivers****
}

\begin{abstract}
This paper aims to analyze border refusals regarding Latin American exports due to non-compliance of technical requirements. For this, three case studies which aim to cover the regional diversity involved are presented: Chile, Costa Rica and the Dominican Republic. Food exports sent to the United States and the European Union from January 2002 to December 2013 were analyzed, focusing on rejections and the reasons why. In this regard, it is noted that the country with the most cases of rejection of exports is the Dominican Republic, the main reason being the presence of pesticides, failures in product manufacturing or because it was filthy or decomposed. For Costa Rica, the main reasons for rejection are the presence of pesticides, failures in manufacturing and the labeling not meeting the requirements of the target markets. Whereas in Chile, the main reasons are that the products were filthy or decomposed as well as there being failures in manufacturing. Considering the results obtained, it can be concluded that Costa Rica and the Dominican Republic have improvements to make mostly in their productive stages, while Chile must do so in its post productive stage. This research is a contribution to the study of the impact of the technical requirements in international trade, as well as to the emerging literature on export refusals.
\end{abstract}

Keywords: International trade. Agricultural products. Technical non-tariff measures. Refusals. Latin America.

\section{Resumen} Instituto de Estudios Internacionales de la Universidad de Chile. Condell 249, Providencia.7500753. Santiago, Chile._jrozas@u. uchile.cl).

**** Consultor, Oficina Regional para América Latina y el Caribe de la Organización de las Naciones Unidas para la Alimentación y la Agricultura. Dag Hammarskjöld 3241, Vitacura.

7630412. (rrivers@gmail.com)

** Profesora asistente, Departamento de Economía Agraria, Facultad de Ciencias Agronómicas de la Universidad de Chile. Santa Chile. (sofiaboza@u.uchile.cl).

*** Núcleo de Estudios en Desarrollo Inter-
El presente trabajo tiene por objeto hacer un análisis de los rechazos en frontera de exportaciones latinoamericanas de alimentos por incumplimiento de requisitos técnicos. Para ello, se presentan tres estudios de caso con los que se trata de abarcar la diversidad regional: Chile, Costa Rica y República Dominicana. Para cada uno de ellos se analizaron las exportaciones 
agroalimentarias enviadas a Estados Unidos y la Unión Europea desde enero del 2002 hasta diciembre de 2013, en base a los rechazos y los motivos. Al respecto, se observa que el país con más casos de rechazo de exportaciones es República Dominicana, siendo el principal motivo la presencia de pesticidas, fallas en la manufactura del producto o porque éste estaba sucio/descompuesto. Para Costa Rica, los principales motivos de rechazo son presencia de pesticidas, fallas de manufactura y etiquetado no acorde a lo exigido en los mercados de destino. Mientras que para Chile los principales motivos son que los productos estaban sucios/descompuestos o con fallas en la manufactura. Considerando los resultados obtenidos, se concluye que Costa Rica y República Dominicana tienen mejoras que realizar principalmente en su etapa productiva, mientras que Chile en su etapa post productiva. Esta investigación supone una contribución al estudio del impacto de los requisitos técnicos en el comercio internacional, así como a la incipiente literatura sobre rechazos de exportaciones, la cual ha tenido un escaso desarrollo para América Latina.

Palabras-clave: Comercio internacional. Productos agroalimentarios. Medidas sanitarias y fitossanitárias. Rechazos. América Latina.

\section{INTRODUCCIÓN}

El concepto de "Seguridad Alimentaria" engloba no solamente el acceso y la disponibilidad por parte de la población de alimentos suficientes, sino que éstos sean inocuos, saludables y nutritivos. Respecto a la inocuidad, la Organización Mundial de la Salud (OMS) la relaciona con la no generación de enfermedades en los consumidores, asociadas éstas a bacterias, virus, parásitos o químicos tóxicos para el organismo. Según FAO la inocuidad es una dimensión indispensable dentro de la noción de "calidad alimentaria", la cual debería estar garantizada, pero no es la única. La calidad comprendería además otras características de los alimentos, como por ejemplo sus cualidades organolépticas, nutricionales, funcionales o incluso las implicaciones sociales y/o ambientales de su producción. Es decir, todo aquello que genere una mayor utilidad al consumidor ${ }^{1}$.

1 ORGANIZACIÓN PARA LA AGRICULTURA Y ALIMENTACIÓN. Inocuidad y calidad de los alimentos en Europa:
La mayoría de las características señaladas tienen en común que no pueden ser comprobadas directamente por el individuo al realizar la compra, e incluso ni siquiera al momento de consumir el producto. Éstas pertenecen a los categorizados como "atributos de creencia", distintos de las experiencias sensoriales, emocionales y racionales que implica habitualmente el proceso de compra $^{3}$. A pesar de lo anterior, las cualidades señaladas pueden tener una influencia muy significativa en la decisión de compra del consumidor, en la medida de su potencial para alterar su satisfacción. En este contexto, para evitar que la asimetría de información derive en fraudes o, por el contrario, en inhibir la adquisición de un producto que efectivamente cumple con características deseadas, se han generado mecanismos tanto públicos como privados con el fin de ofrecer información confiable que pueda guiar el proceso de compra. Inclusive, en el caso en el cual el alimento suponga un riesgo para la salud de los potenciales consumidores, dichos mecanismos evitarían su comercialización.

Lo mencionado se basa en el establecimiento de normas voluntarias u obligatorias, cuyo cumplimiento sea fiscalizado. Cuando nos referimos a la inocuidad de los alimentos, dichas normas suelen ser de carácter obligatorio, impuestas por el sector público. Sin embargo, cuando tienen que ver con otras dimensiones de la calidad alimentaria encuentran cabida aquellas de carácter voluntario, cuya definición puede emerger tanto del sector público como del sector privado. En el caso de los requisitos impuestos por el sector público, con el fin de propender a que éstos sean lo menos lesivos posible para el comercio internacional, los países miembros de la Organización Mundial de Comercio establecieron el marco normativo multilateral al cual deben atender. Lo anterior, quedó reflejado en el Acuerdo sobre Aplicación de Medidas Sanitarias y Fitosanitarias (Acuerdo MSF) y el Acuerdo sobre Obstáculos Técnicos al Comercio (Acuerdo OTC), ambos resultados de la Ronda de Negociaciones de Uruguay.

aspectos relacionados con la calidad, el equilibrio nutricional, la importancia de los terrenos agrícolas y el patrimonio cultural ("terroirs"). In: CONFERENCIA REGIONAL DE LA FAO PARA EUROPA. 24., 2004. 2004.

2 DARBY, Michael R.; KARNI, Edi. Free Competition and the Optimal Amount of Fraud. Journal of Law and Economics, v. 16, n. 1, p. 67-88. 1973.

3 BASHAR, Abu; AHMAD, Irshad; WASI, Mohammad. A Study of Influence of Demographic Factors on Consumer Impulse Buying Behavior. Journal of Management Research, v. 13, n. 3, p. 145-154, 2013. 
Las fallas en el cumplimiento de estos requisitos técnicos pueden motivar el rechazo en frontera de los cargamentos, representando una pérdida tanto de los ingresos esperados por las ventas como del costo del transporte. Asimismo, puede implicar perjuicios a la imagen del país del cual proceden los productos, generando desconfianza para cargamentos a futuro e incluso, en casos particularmente graves, el cierre temporal de las fronteras. Así mismo, da lugar a preguntarse si existen problemas en los productos que se están destinando a mercados externos, si éstos no se replicarán de igual manera, o incluso con más gravedad, para aquellos que se comercializan en el mercado local.

América Latina no está en absoluto al margen de las situaciones mencionadas, dado que como fue señalado, es exportador neto de productos agroalimentarios a países con altos estándares de calidad e inocuidad. En este sentido, de acuerdo a datos del Banco Mundial las exportaciones agrícolas representan más del 20\% del valor total de las exportaciones regionales, con una balanza ampliamente positiva. Los principales destinos de dichas exportaciones son Estados Unidos y la Unión Europea. Estos mercados han experimentado un incremento de los requisitos de calidad e inocuidad en los alimentos importados ${ }^{4}$, por lo que es de suponer que las inspecciones que se realizan en sus fronteras son especialmente exigentes.

En Estados Unidos si bien más de una docena de agencias federales comparten jurisdicción en materia de inocuidad de los alimentos, la Food and Drug Administration (FDA) supervisa la inspección de casi la totalidad de las importaciones, pero debido a sus recursos limitados sólo revisa en frontera el 1\% de los cargamentos, dando prioridad a aquellos posiblemente más riesgosos $^{5}$. El rol de la FDA es garantizar que los alimentos en mal estado, no aptos para el consumo humano o que contengan un mal etiquetado no lleguen al comprador, mediante el rechazo del producto.

4 BOZA, Sofía; FERNÁNDEZ, Felipe. World Trade Organization members' participation in mechanisms under the Sanitary and Phytosanitary Agreement. International Journal of Trade and Global Markets. En prensa.

5 ARTECONA, Raquel; FLORES, Fernando. Observatorio del control aduanero a las importaciones de Estados Unidos: Estándares Técnicos. Washington DC: CEPAL, 2009; GAO. Food Safety: Federal Efforts to Ensure the Safety of Imported Foods are Inconsistent and Unreliable. Report to the Chairman, Permanent Subcommittee on Investigations. Washington DC.: U.S. Senate. 1998; ELDER, David. Ensuring the safety of imported products: consumer updates. 2013.
Para el caso europeo, en el ámbito de la protección sanitaria, actúan los siguientes cuatro órganos: Dirección General de la Salud y Protección de los Consumidores (DG SANCO), Autoridad Europea de Seguridad Alimentaria (EFSA), Comité Permanente de la Cadena Alimentaria y de Sanidad Animal y la Oficina Alimentaria y Veterinaria $(\mathrm{OAV})^{6}$. En este contexto, un instrumento clave de coordinación es el Sistema de Alerta Rápida Para Alimentos y Piensos (RASFF), el cual permite compartir información entre las autoridades de control sanitario mencionadas.

Considerando el contexto presentado, este artículo tiene como objetivo abordar el análisis de los rechazos en frontera de las exportaciones regionales por el no cumplimiento de requisitos técnicos, sanitarios y fitosanitarios. Para ello, se estudiaron tres casos, con los cuales se trata de recoger la diversidad regional: Chile (América del Sur), Costa Rica (América Central) y República Dominicana (El Caribe). En cada caso se analizaron las exportaciones alimentarias enviadas a Estados Unidos y la Unión Europea entre 2002 y 2013, registrando los rechazos de dichas exportaciones y los motivos de los mismos. Los datos necesarios para lo anterior fueron obtenidos del Food and Drug Administration (FDA) para el caso de Estados Unidos y del Sistema de Alerta Rápida para Alimentos y Piensos (RASFF) para la Unión Europea.

\section{Estudios de CASO SOBRE RECHAZOS DE EXPORTACIONES ALIMENTARIAS}

\subsection{Chile}

a) Rechazos en la frontera de Estados Unidos

Entre 2002 y 2013, la FDA registró 607 bloqueos a productos chilenos en la frontera de Estados Unidos, con 635 reportes $^{7}$ cuyos motivos se especifican en la tabla a continuación.

6 BANCO INTERAMERICANO DE DESARROLLO. Gúa para la exportación de productos agrícolas y alimentos a la Unión Europea. 2010.

7 Si bien son 607 los rechazos en las fronteras de Estados Unidos, algunos de los productos implicados tenían más de un motivo para ser rechazados, es por ello que se registró un mayor número de reportes. 
Tabla 1 - Registros de rechazos en EEUU según motivo (2002-2013) \begin{tabular}{|l|c|c|c|c|c|c|c|c|c|c|c|c|c|} 
& 2002 & 2003 & 2004 & 2005 & 2006 & 2007 & 2008 & 2009 & 2010 & 2011 & 2012 & 2013 & Total \\
\hline Pesticida & 8 & 7 & 11 & 5 & 5 & 9 & 3 & 2 & 2 & 12 & 11 & 19 & 94 \\
\hline
\end{tabular}

\begin{tabular}{|l|l|l|l|l|l|l|l|l|l|l|l|l|l|}
\hline Bacteria & 8 & 6 & 7 & 3 & 7 & 1 & 1 & 1 & 12 & 19 & 11 & 17 & 93 \\
\hline Sucio/
\end{tabular}

\begin{tabular}{|l|l|l|l|l|l|l|l|l|l|l|l|l|l|}
\hline $\begin{array}{l}\text { Sucio/ } \\
\text { descompuesto }\end{array}$ & 13 & 12 & 19 & 10 & 10 & 12 & 11 & 44 & 7 & 48 & 4 & 6 & 196 \\
\hline
\end{tabular}

\begin{tabular}{|l|l|l|l|l|l|l|l|l|l|l|l|l|l|}
\hline Fallas & 2 & 21 & 19 & 9 & 7 & 12 & 9 & 2 & 0 & 2 & 48 & 5 & 136
\end{tabular}

\begin{tabular}{|l|l|l|l|l|l|l|l|l|l|l|l|l|l|} 
manufactura & & & & & & & & \\
\hline Venenoso & 2 & 2 & 1 & 2 & 2 & 2 & 0 & 3 & 1 & 3 & 5 & 3 & 26 \\
\hline
\end{tabular}

\begin{tabular}{|l|l|l|l|l|l|l|l|l|l|l|l|l|l|}
\hline Sin permiso & 1 & 1 & 1 & 0 & 0 & 0 & 0 & 0 & 0 & 0 & 0 & 0 & 3 \\
\hline
\end{tabular}

FCE

\begin{tabular}{|l|l|l|l|l|l|l|l|l|l|l|l|l|l|}
\hline Droga & 0 & 0 & 0 & 0 & 1 & 0 & 0 & 4 & 1 & 6 & 0 & 3 & 15 \\
\hline
\end{tabular}

veterinaria

Etiquetado

Total

violaciones

Fuente: Elaboración propia en base a datos de la FDA (2014)

Como se observa, en los 12 años estudiados la principal causa de rechazo de cargamentos 8 es por malas condiciones higiénicas (descomposición principalmente, visible o identificable por malos olores). La segunda causa es por fallas de manufactura relacionadas también a aspectos sanitarios, es decir, productos rechazados por haberse demostrado su manufactura o empaque en condiciones poco higiénicas pero no relacionadas a descomposición natural de los alimentos, sino por contaminación derivada de malas prácticas. Es necesario destacar la cantidad de productos rechazados sólo por no cumplir con las normas de etiquetado, pues estos son productos a priori en buenas condiciones, pero acompañados de una etiqueta sin el nombre del fabricante, con una denominación correspondiente a otro alimento o no estaban en inglés.

En la tabla 2 se presenta el número de rechazos de los cargamentos por tipo y por año. Los envíos con más rechazos son los pescados (entre ellos jurel, salmón, pez espada y anchoveta), siendo las causas principales el encontrarse en estado de descomposición, o por ser considerados venenosos por índices de mercurio que superaban la norma. El segundo lugar en número de rechazos corresponde a frutas frescas, siendo el principal motivo del bloqueo, la presencia de pesticidas no permitidos. Por otra parte, los frutos secos y crustáceos y mariscos, tienen mayor número de rechazos por descomposición y los jugos de fruta y otros productos industriales procesados (como pastas, golosinas, chocolates y refrescos) no eran acompañados de una etiqueta adecuada.

8 Entendiendo cargamento conforme a la definición realizada por el Departamento de Agricultura de Estados Unidos como un lote único de un determinado producto alimenticio ofrecido por un transportista determinado en un determinado lugar y tiempo (BUZBY; UNNEVEHR; ROBERTS, 2008).
Tabla 2 - Registros de rechazos por producto y por año en EEUU (2002-2013)

\begin{tabular}{|c|c|c|c|c|c|c|c|c|c|c|} 
& Pescados & Mariscos & Verduras & Frutas & $\begin{array}{c}\text { Frutos } \\
\text { secos }\end{array}$ & Hongos & Especias & Jugos & Lácteos & $\begin{array}{c}\text { Otros } \\
\text { indus. }\end{array}$ \\
\hline 2002 & 15 & 5 & 1 & 5 & 6 & 2 & 0 & 3 & 1 & 0 \\
\hline 2003 & 19 & 8 & 3 & 9 & 6 & 1 & 0 & 1 & 3 & 1 \\
\hline 2004 & 27 & 10 & 2 & 13 & 8 & 0 & 0 & 0 & 1 & 5 \\
\hline 2005 & 9 & 6 & 2 & 5 & 4 & 0 & 0 & 1 & 0 & 2 \\
\hline 2006 & 24 & 1 & 1 & 7 & 1 & 0 & 0 & 0 & 0 & 1 \\
\hline 2007 & 17 & 1 & 2 & 9 & 1 & 0 & 0 & 0 & 4 & 2 \\
\hline 2008 & 7 & 2 & 3 & 2 & 7 & 0 & 0 & 2 & 0 & 6 \\
\hline 2009 & 16 & 3 & 7 & 37 & 0 & 0 & 1 & 0 & 0 & 7 \\
\hline 2010 & 8 & 8 & 1 & 3 & 4 & 0 & 0 & 0 & 0 & 2 \\
\hline 2011 & 23 & 20 & 1 & 13 & 34 & 0 & 0 & 0 & 0 & 0 \\
\hline 2012 & 65 & 1 & 0 & 12 & 2 & 0 & 0 & 0 & 0 & 0 \\
\hline 2013 & 24 & 5 & 2 & 17 & 5 & 0 & 0 & 1 & 0 & 1 \\
\hline Total & 254 & 70 & 25 & 132 & 78 & 3 & 1 & 8 & 9 & 27 \\
\hline
\end{tabular}

Fuente. Elaboración propia en base a datos de la FDA (2014)

Finalmente, considerando el total de productos rechazados, se observa un incremento drástico el año 2011 pero con una caída en el 2013, a pesar del aumento de exportaciones silvoagropecuarias a Estados Unidos en dicho año.

\section{b) Rechazos en la frontera de la Unión Europea}

Existen 217 registros de cargamentos sometidos a notificaciones. De estos, 90 son medidas de información, 33 de alerta y 94 de rechazo de productos ${ }^{9}$ (tabla 3 ). Las causas específicas por año, se presentan en la tabla 4.

Tabla 3 - Cantidad de notificaciones de la UE por tipo y por año (2002 - 2013)

\begin{tabular}{|l|c|c|c|c|c|c|c|c|c|c|c|c|c|} 
& 2002 & 2003 & 2004 & 2005 & 2006 & 2007 & 2008 & 2009 & 2010 & 2011 & 2012 & 2013 & Total \\
\hline Información & 5 & 3 & 8 & 10 & 6 & 12 & 5 & 10 & 13 & 10 & 3 & 5 & 90 \\
\hline Alerta & 1 & 1 & 1 & 5 & 3 & 8 & 1 & 1 & 4 & 6 & 1 & 1 & 33 \\
\hline Rechazo & 0 & 0 & 0 & 0 & 0 & 0 & 2 & 20 & 7 & 42 & 18 & 5 & 94 \\
\hline Total & 6 & 4 & 9 & 15 & 9 & 20 & 8 & 31 & 24 & 58 & 22 & 11 & 217 \\
\hline
\end{tabular}

Fuente: Elaboración propia en base a información del RASFF (2014)

Tabla 4 - Registros de notificaciones en la Unión Europea por motivo (2002 - 2013)

\begin{tabular}{|l|c|c|c|c|c|c|c|c|c|c|c|c|c|c|c|} 
& 2002 & 2003 & 2004 & 2005 & 2006 & 2007 & 2008 & 2009 & 2010 & 2011 & 2012 & 2013 & Total \\
\hline Pesticida & 0 & 0 & 0 & 2 & 1 & 7 & 2 & 2 & 4 & 0 & 1 & 0 & 19 \\
\hline $\begin{array}{l}\text { Bacteria y } \\
\text { virus }\end{array}$ & 5 & 2 & 9 & 4 & 2 & 4 & 1 & 1 & 3 & 20 & 2 & 0 & 53 \\
\hline $\begin{array}{l}\text { Sucio/ } \\
\text { descompuesto }\end{array}$ & 0 & 0 & 0 & 0 & 0 & 3 & 1 & 15 & 5 & 16 & 10 & 3 & 53 \\
\hline
\end{tabular}

9 Las notificaciones de alerta se realizan en el caso de que estén a la venta alimentos o piensos que presenten un grave riesgo y deban emprenderse acciones de forma rápida. Las notificaciones de información se usan en la misma situación, pero cuando los otros miembros no deben adoptar medidas de forma rápida porque el producto no se encuentra en el mercado o el riesgo no se considera grave. El rechazo en frontera afecta a las remesas de alimentos y piensos que se han examinado y rechazado en las fronteras exteriores de la UE al detectarse un riesgo sanitario. 
\begin{tabular}{|l|l|l|l|l|l|l|l|l|l|l|l|l|l|l|l|}
2002 & 2003 & 2004 & 2005 & 2006 & 2007 & 2008 & 2009 & 2010 & 2011 & 2012 & 2013 & Total \\
\hline
\end{tabular}

\begin{tabular}{|c|c|c|c|c|c|c|c|c|c|c|c|c|c|}
\hline $\begin{array}{l}\text { Fallas } \\
\text { manufactura }\end{array}$ & 0 & 0 & 0 & 2 & 1 & 3 & 3 & 7 & 7 & 10 & 6 & 2 & 41 \\
\hline Venenoso & 0 & 1 & 0 & 5 & 5 & 2 & 1 & 5 & 5 & 10 & 3 & 5 & 42 \\
\hline Sin permiso & 0 & 0 & 0 & 0 & 0 & 0 & 0 & 0 & 0 & 0 & 0 & 0 & 0 \\
\hline $\begin{array}{l}\text { Droga } \\
\text { veterinaria }\end{array}$ & 1 & 1 & 0 & 2 & 0 & 0 & 0 & 0 & 0 & 2 & 0 & 0 & 6 \\
\hline Etiquetado & 0 & 0 & 0 & 0 & 0 & 1 & 0 & 1 & 0 & 0 & 0 & 1 & S \\
\hline $\begin{array}{l}\text { Total } \\
\text { violaciones }\end{array}$ & 6 & 4 & 9 & 15 & 9 & 20 & 8 & 31 & 24 & 58 & 22 & 11 & 217 \\
\hline
\end{tabular}

Fuente: Elaboración propia en base a información del RASFF (2014)

Nuevamente, la principal causa de notificación de productos alimentarios chilenos, corresponde a productos descompuestos o sucios. La misma cantidad de notificaciones corresponde a presencia de bacterias y virus, principalmente Salmonella, y E. coli. Además, un número importante de productos fueron notificados por considerarse venenosos (principalmente productos del mar con elevados niveles de mercurio, y crustáceos y mariscos con presencia de metales pesados). Toma asimismo importancia las etapas posteriores a la extracción y/o producción, ya que por ejemplo muchos productos del mar fueron notificados por ruptura de la cadena de frío en el transporte.

La tabla 5 muestra la cantidad de cargamentos notificados desde enero del 2002 hasta diciembre del 2013 según productos. La lista está encabezada por los productos del mar y seguida por las frutas frescas, cuyo motivo de rechazo es principalmente presencia de pesticidas o fungicidas. Dentro del ítem "otros industriales", se encuentra la harina de pescado, golosinas, vinos y productos de panadería principalmente.

Tabla 5 - Registro de notificaciones por producto y por año en la UE (2002-2013)

\begin{tabular}{|c|c|c|c|c|c|c|c|c|c|c|}
\hline & Pescados & $\begin{array}{c}\text { Carne } \\
\text { aves }\end{array}$ & Marisco & Verduras & $\begin{array}{c}\text { Frutas } \\
\text { frescas }\end{array}$ & $\begin{array}{c}\text { Frutos } \\
\text { secos }\end{array}$ & Hongos & Especias & Lácteos & $\begin{array}{c}\text { Otros } \\
\text { indus. }\end{array}$ \\
\hline 2002 & 0 & 4 & 2 & 0 & 0 & 0 & 0 & 0 & 0 & 0 \\
\hline 2003 & 0 & 0 & 3 & 0 & 0 & 0 & 0 & 0 & 0 & 1 \\
\hline 2004 & 0 & 0 & 9 & 0 & 0 & 0 & 0 & 0 & 0 & 0 \\
\hline 2005 & 3 & 0 & 5 & 0 & 3 & 3 & 0 & 0 & 0 & 1 \\
\hline 2006 & 2 & 0 & 4 & 0 & 2 & 0 & 0 & 0 & 0 & 1 \\
\hline 2007 & 4 & 0 & 3 & 0 & 6 & 5 & 0 & 0 & 0 & 2 \\
\hline 2008 & 1 & 1 & 1 & 0 & 2 & 1 & 1 & 1 & 0 & 0 \\
\hline 2009 & 13 & 0 & 5 & 0 & 6 & 4 & 0 & 0 & 1 & 2 \\
\hline 2010 & 10 & 1 & 2 & 0 & 7 & 3 & 0 & 0 & 0 & 1 \\
\hline 2011 & 18 & 0 & 10 & 1 & 2 & 5 & 0 & 0 & 0 & 22 \\
\hline 2012 & 3 & 0 & 11 & 0 & 2 & 3 & 0 & 0 & 0 & 3 \\
\hline 2013 & 3 & 2 & 5 & 0 & 1 & 0 & 0 & 0 & 0 & 0 \\
\hline Total & 57 & 8 & 60 & 1 & 31 & 24 & 1 & 1 & 1 & 33 \\
\hline
\end{tabular}

Fuente: Elaboración propia en base a información del RASFF (2014)
Finalmente, el mayor número de notificaciones ocurrió el 2011, pero con tendencias al alza en el número de notificaciones desde el 2003, año en que comenzó a regir el acuerdo comercial entre Chile y la UE.

\subsection{Costa Rica}

a) Rechazos en la frontera de Estados Unidos

Se registraron 419 reportes de violaciones de requisitos técnicos de productos costarricenses en las fronteras de Estados Unidos entre enero del 2002 y diciembre del 2013, para 392 cargamentos de productos rechazados. La cantidad de rechazos por causa específica se presenta en la tabla 6 . Como se observa, la principal causa de rechazos de productos es por presencia de pesticidas, principalmente en frutas frescas, verduras y tubérculos, mientras que la segunda causa es haberse comprobado fallas sanitarias en la manufacturación de los productos. La tercera causa en importancia es por fallas en etiquetado, seguida por el estado de descomposición del producto.

Tabla 6 - Registros de rechazos en Estados Unidos por motivo (2002 - 2013)

\begin{tabular}{|l|c|c|c|c|c|c|c|c|c|c|c|c|c|}
\hline & 2002 & 2003 & 2004 & 2005 & 2006 & 2007 & 2008 & 2009 & 2010 & 2011 & 2012 & 2013 & Total \\
\hline Pesticida & 8 & 28 & 4 & 9 & 9 & 6 & 0 & 0 & 1 & 11 & 44 & 19 & 139 \\
\hline Bacteria & 2 & 2 & 4 & 2 & 4 & 0 & 0 & 2 & 3 & 9 & 1 & 1 & 30 \\
\hline $\begin{array}{l}\text { Sucio/ } \\
\text { descompuesto }\end{array}$ & 6 & 8 & 8 & 2 & 3 & 4 & 4 & 6 & 2 & 3 & 5 & 1 & 52 \\
\hline $\begin{array}{l}\text { Fallas } \\
\text { manufactura }\end{array}$ & 6 & 7 & 26 & 22 & 17 & 3 & 9 & 3 & 1 & 2 & 10 & 5 & 111 \\
\hline $\begin{array}{l}\text { Venenoso } \\
\text { Sin permiso } \\
\text { FCE }\end{array}$ & 2 & 3 & 1 & 2 & 1 & 6 & 0 & 1 & 0 & 0 & 1 & 1 & 18 \\
\hline $\begin{array}{l}\text { Droga } \\
\text { veterinaria }\end{array}$ & 0 & 0 & 0 & 0 & 0 & 0 & 0 & 0 & 0 & 0 & 0 & 0 & 0 \\
\hline Etiquetado & 5 & 1 & 17 & 1 & 9 & 5 & 6 & 4 & 0 & 1 & 8 & 9 & 66 \\
\hline $\begin{array}{l}\text { Total } \\
\text { violaciones }\end{array}$ & 29 & 49 & 62 & 38 & 44 & 24 & 19 & 16 & 7 & 26 & 69 & 36 & 419 \\
\hline
\end{tabular}

Fuente: Elaboración propia en base a datos de la FDA (2014)

En la tabla 7, se especifica la naturaleza de los productos rechazados. Estos son principalmente pescados, verduras y tubérculos. Si bien el ítem "otros industriales" tiene un mayor número de rechazos, está compuesto por una amplia gama de productos, entre ellos golosinas, artículos de pan y pastelería y salsas de origen vegetal y cárnico. 
Tabla 7 - Registros de rechazos por naturaleza del producto y por año (2002-2013)

\begin{tabular}{|c|c|c|c|c|c|c|c|c|c|} 
& Pescados & Mariscos & $\begin{array}{c}\text { Hort. y } \\
\text { tuberc. }\end{array}$ & Frutas & $\begin{array}{c}\text { Legum. } \\
\text { y cereal }\end{array}$ & Especias & Jugos & Lácteos & $\begin{array}{c}\text { Otros } \\
\text { indus. }\end{array}$ \\
\hline 2002 & 8 & 1 & 2 & 7 & 0 & 8 & 0 & 0 & 1 \\
\hline 2003 & 10 & 1 & 8 & 4 & 1 & 19 & 0 & 1 & 4 \\
\hline 2004 & 9 & 1 & 6 & 5 & 2 & 7 & 0 & 10 & 19 \\
\hline 2005 & 6 & 2 & 3 & 6 & 0 & 0 & 0 & 2 & 18 \\
\hline 2006 & 9 & 0 & 8 & 2 & 0 & 0 & 0 & 1 & 17 \\
\hline 2007 & 10 & 0 & 3 & 4 & 0 & 0 & 3 & 0 & 2 \\
\hline 2008 & 4 & 0 & 0 & 0 & 0 & 0 & 0 & 0 & 10 \\
\hline 2009 & 3 & 0 & 0 & 2 & 1 & 1 & 1 & 0 & 4 \\
\hline 2010 & 1 & 0 & 2 & 1 & 0 & 3 & 0 & 0 & 0 \\
\hline 2011 & 1 & 0 & 6 & 4 & 1 & 13 & 0 & 0 & 1 \\
\hline 2012 & 15 & 0 & 21 & 11 & 2 & 7 & 2 & 0 & 11 \\
\hline 2013 & 1 & 0 & 8 & 3 & 7 & 5 & 0 & 0 & 10 \\
\hline Total & 77 & 5 & 67 & 49 & 14 & 63 & 6 & 14 & 97 \\
\hline
\end{tabular}

Fuente: Elaboración propia en base a datos de la FDA (2014)

En cuanto al total de cargamentos rechazados, si bien se observó una tendencia a su disminución hasta el 2010, tuvo lugar un fuerte aumento el año 2012.

\section{b) Rechazos en la frontera de la Unión Europea}

Entre 2002 y 2013 la UE emitió 30 reportes contra productos agrícolas costarricenses, de estos 6 son correspondientes a rechazos en frontera (tabla 8).

Tabla 8 - Cantidad de notificaciones de la UE por tipo y por año (2002-2013)

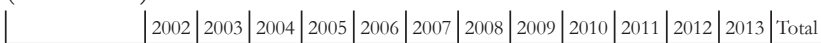
\begin{tabular}{|l|l|l|l|l|l|l|l|l|l|l|l|l|l|}
\hline Información & 0 & 0 & 0 & 1 & 0 & 3 & 1 & 0 & 2 & 1 & 0 & 5 & 13 \\
\hline Al & 0 & 0 & 0 & 3 & 2 & 2 & 1 & 0 & 0 & 0 & 1 & 2 & 11
\end{tabular} \begin{tabular}{|l|c|c|c|c|c|c|c|c|c|c|c|c|c|}
\hline Alerta & 0 & 0 & 0 & 3 & 2 & 2 & 1 & 0 & 0 & 0 & 1 & 2 & 11 \\
\hline
\end{tabular} \begin{tabular}{|l|c|c|c|c|c|c|c|c|c|c|c|c|c|}
\hline Rechazo & 0 & 0 & 0 & 0 & 0 & 0 & 1 & 3 & 2 & 0 & 0 & 0 & 6 \\
\hline
\end{tabular} \begin{tabular}{|l|l|l|l|l|l|l|l|l|l|l|l|l|l|}
\hline Total & 0 & 0 & 0 & 4 & 2 & 5 & 3 & 3 & 4 & 1 & 1 & 7 & 30 \\
\hline
\end{tabular}

Fuente: Elaboración propia en base a información del RASFF (2014)

Las notificaciones específicas por año se presentan en la tabla 9.

Tabla 9 - Registros de notificaciones en UE según motivos (2002 - 2013)

\begin{tabular}{|l|c|c|c|c|c|c|c|c|c|c|c|c|c|}
\hline & 2002 & 2003 & 2004 & 2005 & 2006 & 2007 & 2008 & 2009 & 2010 & 2011 & 2012 & 2013 & Total \\
\hline Pesticida & 0 & 0 & 0 & 0 & 0 & 3 & 2 & 1 & 1 & 1 & 0 & 6 & 14 \\
\hline Bacteria & 0 & 0 & 0 & 0 & 2 & 1 & 0 & 0 & 0 & 0 & 0 & 1 & 4 \\
\hline $\begin{array}{l}\text { Sucio/ } \\
\text { descompuesto }\end{array}$ & 0 & 0 & 0 & 0 & 0 & 0 & 1 & 1 & 2 & 0 & 0 & 0 & 4 \\
\hline $\begin{array}{l}\text { Fallas } \\
\text { manufactura }\end{array}$ & 0 & 0 & 0 & 2 & 0 & 1 & 0 & 1 & 1 & 0 & 1 & 0 & 6 \\
\hline Venenoso & 0 & 0 & 0 & 0 & 0 & 0 & 0 & 0 & 0 & 0 & 0 & 0 & 0 \\
\hline Sin permiso & 0 & 0 & 0 & 1 & 0 & 0 & 0 & 0 & 0 & 0 & 0 & 0 & 1 \\
\hline $\begin{array}{l}\text { Proga } \\
\text { veterinaria }\end{array}$ & 0 & 0 & 0 & 1 & 0 & 0 & 0 & 0 & 0 & 0 & 0 & 0 & 1 \\
\hline Etiquetado & 0 & 0 & 0 & 2 & 0 & 0 & 0 & 0 & 0 & 0 & 0 & 0 & 2 \\
\hline $\begin{array}{l}\text { Total } \\
\text { violaciones }\end{array}$ & 0 & 0 & 0 & 6 & 2 & 5 & 3 & 3 & 4 & 1 & 1 & 7 & 30 \\
\hline
\end{tabular}

Fuente: Elaboración propia en base a información del RASFF (2014)
Se observa que la principal causa de notificaciones de la Unión Europea para productos de Costa Rica es por la presencia de pesticidas seguido por manufactura en malas condiciones higiénicas o ruptura de la cadena de frío en el transporte. No hubo en ese periodo, notificaciones por incumplimiento a las normas de etiquetado, ni presencia de drogas veterinarias en los productos de origen animal. La naturaleza de los productos notificados se muestra en la tabla 10 , siendo las frutas frescas los productos con un mayor número de acciones emitidas.

Tabla 10 - Registros de notificaciones por producto y por año

\begin{tabular}{|l|c|c|c|c|c|} 
& Pescados & $\begin{array}{c}\text { Frutas } \\
\text { frescas }\end{array}$ & Tubérculos & Café & $\begin{array}{c}\text { Comida } \\
\text { dietética }\end{array}$ \\
\hline 2002 & 0 & 0 & 0 & 0 & 0 \\
\hline 2003 & 0 & 0 & 0 & 0 & 0 \\
\hline 2004 & 0 & 0 & 0 & 0 & 0 \\
\hline 2005 & 3 & 0 & 0 & 0 & 1 \\
\hline 2006 & 2 & 0 & 0 & 0 & 0 \\
\hline 2007 & 1 & 4 & 0 & 0 & 0 \\
\hline 2008 & 0 & 2 & 0 & 1 & 0 \\
\hline 2009 & 1 & 0 & 2 & 0 & 0 \\
\hline 2010 & 1 & 3 & 0 & 0 & 0 \\
\hline 2011 & 0 & 1 & 0 & 0 & 0 \\
\hline 2012 & 0 & 0 & 0 & 0 & 1 \\
\hline 2013 & 0 & 7 & 0 & 0 & 0 \\
\hline Total & 8 & 17 & 2 & 1 & 2 \\
\hline
\end{tabular}

Fuente: Elaboración propia en base a información del RASFF (2014)

En cuanto a la cantidad de cargamentos notificados por año, se observa que el mayor número se registró el año 2013 con 7 notificaciones, seguido por 5 notificaciones ocurridas el 2007.

\subsection{República Dominicana}

a) Rechazos en la frontera de Estados Unidos

Desde enero de 2002 hasta diciembre de 2013, 3.355 cargamentos dominicanos fueron rechazados en las fronteras de Estados Unidos, presentando algunos de estos más de un motivo de rechazo, con 3.364 registros que son detallados en la tabla a continuación.

Tabla 11 - Registros de rechazos en Estados Unidos por motivo (2002 - 2013)

\begin{tabular}{|c|c|c|c|c|c|c|c|c|c|c|c|c|c|}
\hline & 2002 & 2003 & 2004 & 2005 & 2006 & 2007 & 2008 & 2009 & 2010 & 2011 & 2012 & 2013 & \begin{tabular}{|l|} 
Total \\
\end{tabular} \\
\hline Pesticida & 161 & 292 & 392 & 330 & 742 & \begin{tabular}{|l|}
494 \\
\end{tabular} & 47 & 29 & 39 & 34 & 31 & 127 & 2718 \\
\hline Bacteria & 0 & 0 & 1 & 0 & 0 & 0 & 0 & 5 & 12 & 14 & 7 & 15 & 54 \\
\hline \begin{tabular}{|l|} 
Sucio/ \\
descompuesto
\end{tabular} & 5 & 12 & 50 & 12 & 7 & 5 & 18 & 2 & 4 & 6 & 10 & 46 & 177 \\
\hline \begin{tabular}{|l|} 
Fallas \\
manufactura
\end{tabular} & 5 & 2 & 22 & 32 & 11 & 10 & 11 & 9 & 7 & 13 & 23 & 65 & 210 \\
\hline Venenoso & 1 & 0 & 0 & 1 & 1 & 1 & 3 & 5 & 6 & 0 & 3 & 0 & 21 \\
\hline
\end{tabular}




\begin{tabular}{|l|c|c|c|c|c|c|c|c|c|c|c|c|c|}
\hline & 2002 & 2003 & 2004 & 2005 & 2006 & 2007 & 2008 & 2009 & 2010 & 2011 & 2012 & 2013 & Total \\
\hline $\begin{array}{l}\text { Sin permiso } \\
\text { FCE }\end{array}$ & 0 & 0 & 0 & 1 & 1 & 1 & 2 & 0 & 0 & 5 & 0 & 4 & 14 \\
\hline $\begin{array}{l}\text { Droga } \\
\text { veterinaria }\end{array}$ & 0 & 0 & 0 & 0 & 0 & 0 & 0 & 0 & 0 & 0 & 0 & 0 & 0 \\
\hline Etiquetado & 11 & 14 & 26 & 6 & 22 & 13 & 6 & 3 & 15 & 10 & 17 & 27 & 170 \\
\hline $\begin{array}{l}\text { Total } \\
\text { violaciones }\end{array}$ & 183 & 320 & 491 & 382 & 784 & 524 & 87 & 53 & 83 & 82 & 91 & 284 & 3364 \\
\hline
\end{tabular}

Fuente: Elaboración propia en base a datos de la FDA (2014)

El principal motivo de rechazo de productos dominicanos es por presencia de pesticidas y luego por fallas comprobables en la manufactura del producto, siendo manipulado o envasado en condiciones higiénicas que no cumplían con las normas requeridas para ingresar al mercado estadounidense.

Por otra parte, los productos más rechazados son verduras, frutas utilizadas como hortalizas, tubérculos, frutas frescas y luego leguminosas y cereales (tabla 12).

Tabla 12 - Cantidad de rechazos por producto y año en Estados Unidos (2002-2013)

\begin{tabular}{|c|c|c|c|c|c|c|c|c|c|}
\hline & Pescados & Mariscos & $\begin{array}{c}\text { Hort. } y \\
\text { tuberc. }\end{array}$ & Frutas & $\begin{array}{c}\text { Legum. } y \\
\text { cereal }\end{array}$ & Especias & Jugos & Lácteos & $\begin{array}{c}\text { Otros } \\
\text { indus. }\end{array}$ \\
\hline 2002 & 0 & 1 & 129 & 22 & 17 & 3 & 1 & 1 & 8 \\
\hline 2003 & 0 & 4 & 192 & 68 & 39 & 0 & 0 & 1 & 11 \\
\hline 2004 & 2 & 0 & 306 & 91 & 93 & 5 & 2 & 56 & 9 \\
\hline 2005 & 0 & 0 & 243 & 20 & 79 & 1 & 1 & 35 & 3 \\
\hline 2006 & 0 & 0 & 382 & 204 & 199 & 3 & 1 & 5 & 4 \\
\hline 2007 & 0 & 0 & 298 & 130 & 74 & 0 & 7 & 2 & 12 \\
\hline 2008 & 0 & 1 & 39 & 8 & 13 & 0 & 11 & 0 & 15 \\
\hline 2009 & 0 & 0 & 24 & 9 & 3 & 1 & 3 & 0 & 12 \\
\hline 2010 & 0 & 0 & 49 & 8 & 3 & 0 & 7 & 0 & 16 \\
\hline 2011 & 0 & 0 & 46 & 4 & 2 & 2 & 1 & 5 & 16 \\
\hline 2012 & 0 & 1 & 22 & 9 & 4 & 1 & 4 & 10 & 20 \\
\hline 2013 & 0 & 1 & 82 & 49 & 24 & 0 & 3 & 34 & 29 \\
\hline Total & 2 & 8 & 1812 & 622 & 550 & 16 & 41 & 149 & 155 \\
\hline
\end{tabular}

Fuente: Elaboración propia en base a datos de la FDA (2014)

Agrupando por año, se observa que el mayor número de productos rechazados ocurrió el año 2006, para descender abruptamente luego del 2007 por mejora en las prácticas productivas, de inspección de los productos a exportar o por salida del mercado de los productores y/o exportadores a los que se les rechazaba un gran número de mercancías.

\section{b) Rechazos en la frontera de la Unión Europea}

$\mathrm{Al}$ respecto, desde enero de 2002 hasta diciembre de 2013, existen 104 notificaciones de acciones tomadas en contra de productos agropecuarios dominicanos en el mercado europeo. De estas, 28 son notificaciones de información, 1 es de alerta y 75 son de rechazo de productos en frontera (tabla 13).
Tabla 13 - Cantidad de notificaciones de la UE por tipo y por año (2002 - 2013)

\begin{tabular}{|l|c|c|c|c|c|c|c|c|c|c|c|c|c|} 
& 2002 & 2003 & 2004 & 2005 & 2006 & 2007 & 2008 & 2009 & 2010 & 2011 & 2012 & 2013 & Total \\
\hline Información & 0 & 0 & 0 & 2 & 4 & 4 & 2 & 0 & 2 & 6 & 7 & 1 & 28 \\
\hline Alerta & 0 & 0 & 0 & 0 & 0 & 0 & 1 & 0 & 0 & 0 & 0 & 0 & 1 \\
\hline Rechazo & 0 & 0 & 0 & 0 & 0 & 0 & 1 & 0 & 12 & 15 & 27 & 20 & 75 \\
\hline Total & 0 & 0 & 0 & 2 & 4 & 4 & 4 & 0 & 14 & 21 & 34 & 21 & 104 \\
\hline
\end{tabular}

Fuente: Elaboración propia en base a información del RASFF (2014)

Las razones de las notificaciones emitidas son principalmente por presencia de pesticidas (100 notificaciones); sin embargo, en el periodo también existen 3 notificaciones acusando productos descompuestos o sucios y 1 fallas sanitarias en la manufactura o transporte. No existe otro tipo de notificación en el periodo (tabla 14).

Tabla 14 - Registros de notificaciones en la Unión Europea (2002 - 2013)

\begin{tabular}{|c|c|c|c|c|c|c|c|c|c|c|c|c|c|}
\hline & 2002 & 2003 & 2004 & 2005 & 2006 & 2007 & 2008 & 2009 & 2010 & 2011 & 2012 & 2013 & Total \\
\hline Pesticida & 0 & 0 & 0 & 1 & 4 & 4 & 4 & 0 & 14 & 20 & 32 & 21 & 100 \\
\hline $\begin{array}{l}\begin{array}{l}\text { Bacteria y } \\
\text { virus }\end{array} \\
\end{array}$ & 0 & 0 & 0 & 0 & 0 & 0 & 0 & 0 & 0 & 0 & 0 & 0 & 0 \\
\hline $\begin{array}{l}\text { Sucio/ } \\
\text { descompuesto }\end{array}$ & 0 & 0 & 0 & 0 & 0 & 0 & 0 & 0 & 0 & 1 & 2 & 0 & 3 \\
\hline \begin{tabular}{|l} 
Fallas \\
manufactura
\end{tabular} & 0 & 0 & 0 & 1 & 0 & 0 & 0 & 0 & 0 & 0 & 0 & 0 & 1 \\
\hline Venenoso & 0 & 0 & 0 & 0 & 0 & 0 & 0 & 0 & 0 & 0 & 0 & 0 & 0 \\
\hline Sin permiso & 0 & 0 & 0 & 0 & 0 & 0 & 0 & 0 & 0 & 0 & 0 & 0 & 0 \\
\hline \begin{tabular}{|l|} 
Droga \\
veterinaria \\
\end{tabular} & 0 & 0 & 0 & 0 & 0 & 0 & 0 & 0 & 0 & 0 & 0 & 0 & 0 \\
\hline Etiquetado & 0 & 0 & 0 & 0 & 0 & 0 & 0 & 0 & 0 & 0 & 0 & 0 & 0 \\
\hline $\begin{array}{l}\text { Total } \\
\text { violaciones }\end{array}$ & 0 & 0 & 0 & 2 & 4 & 4 & 4 & 0 & 14 & 21 & 34 & 21 & 104 \\
\hline
\end{tabular}

Fuente: Elaboración propia en base a información del RASFF (2014)

Analizando la tipología de los productos notificados (tabla 15), se observa que las verduras, se encuentran en primer lugar, seguidas de las leguminosas y posteriormente de las frutas frescas. Por su parte, el año 2012 es el que tuvo mayor número de notificaciones.

Tabla 15 - Cantidad de notificaciones por producto y año en la UE (2002-2013)

\begin{tabular}{|l|c|c|c|c|c|c|}
\hline & Verduras & $\begin{array}{c}\text { Frutas } \\
\text { frescas }\end{array}$ & $\begin{array}{c}\text { Frutos } \\
\text { secos }\end{array}$ & Legumbres & Tubérculos & Chocolate \\
\hline 2002 & 0 & 0 & 0 & 0 & 0 & 0 \\
\hline 2003 & 0 & 0 & 0 & 0 & 0 & 0 \\
\hline 2004 & 0 & 0 & 0 & 0 & 0 & 0 \\
\hline 2005 & 0 & 1 & 1 & 0 & 0 & 0 \\
\hline 2006 & 1 & 0 & 0 & 3 & 0 & 0 \\
\hline 2007 & 2 & 1 & 0 & 1 & 0 & 0 \\
\hline 2008 & 1 & 1 & 0 & 2 & 0 & 0 \\
\hline 2009 & 0 & 0 & 0 & 0 & 0 & 0 \\
\hline 2010 & 12 & 0 & 0 & 2 & 0 & 0 \\
\hline 2011 & 10 & 3 & 0 & 3 & 5 & 0 \\
\hline 2012 & 17 & 8 & 0 & 8 & 0 & 1 \\
\hline 2013 & 14 & 1 & 0 & 6 & 0 & 0 \\
\hline Total & 57 & 15 & 1 & 25 & 5 & 1 \\
\hline
\end{tabular}

Fuente: Elaboración propia en base a información del RASFF (2014) 


\section{Consideraciones finales}

Los resultados de rechazos de exportaciones en frontera encontrados en este estudio sugieren, entre otras cosas, el nivel de conocimiento o de información que maneja la industria privada respecto de los requerimientos de sus clientes en el extranjero y de la legislación internacional que rige el comercio de alimentos a nivel global; la capacidad de supervisión y de gestión que tienen los países para verificar la producción de alimentos, en este caso en particular sobre los que se exportan; cifras y datos concretos para priorizar acciones, tomar decisiones sobre qué aspectos reforzar y sobre qué materias fortalecer. Mientras más información de este tipo se tenga o se pueda acceder, de mayor calidad van a ser las decisiones que se tomen para mejorar la situación.

En América Latina y el Caribe, donde muchos de sus países son exportadores netos de alimentos, el fortalecimiento de los sistemas de control es de vital importancia, no tan solo para evitar que productos puedan ocasionar daños a la salud pública, animal y vegetal, sino como un medio para fomentar el comercio internacional de alimentos. Existen numerosos registros en los principales mercados notificando el rechazo de envíos por fallas evitables. Considerando los casos estudiados, Costa Rica y República Dominicana tienen problemas principalmente en su etapa productiva, mientras que Chile en su etapa post productiva. Al respecto, si los países en estudio enfrentan importantes desafíos comunes para superar obstáculos que les impiden garantizar hoy el nivel de inocuidad de los alimentos exportados, siendo estos más rigurosos, cabe preguntarse cómo es el nivel de inocuidad de los consumidos en el mercado interno.

Lamentablemente, una de las limitaciones del presente estudio es que no fue posible con la información disponible determinar la cantidad exacta de alimentos rechazados y por ende los valores relacionados a pérdidas por rechazos en frontera, pues sólo se contó con notificaciones de rechazo correspondientes a cada incumplimiento, sin especificar otras unidades. Además se desconocen los formatos de venta de los productos rechazados, dato importante al buscar valorizar, pues algunos formatos adquieren precios significativamente superiores a otros. De hecho, el Departamento de Agricultura de Estados Unidos reconoce que la información entregada por la FDA es incompleta. Aun así, estos datos podrían ser estimados bajo cálculos indirectos basados en suposiciones de capacidad de contenedores rechazados y valores de mercado de las mercancías notificadas. Lo que sí está claro es que muchos rechazos en frontera de productos agroalimentarios serían evitados con un uso adecuado de pesticidas respetando los períodos de carencia, invirtiendo en mecanismos de transporte que aseguren cadena de frío ininterrumpida, acompañando los productos de etiquetas acorde a lo demandado por el importador e informándose de los productos anexos permitidos en los distintos mercados, como conservantes, abrillantadores o algún otro aditivo.

Considerando lo anterior, los gobiernos de la región deben visualizar la inocuidad alimentaria como un tema trascendental, comprometiendo mayores recursos en primera instancia para acercar la realidad de cada uno de estos países a los estándares esperados de países desarrollados, mejorando los sistemas de control de alimentos y más aún, la legislación y los procesos de inspección desde una perspectiva de análisis de riesgo, para reducir gastos en salud pública derivados de Enfermedades de Transmisión por Alimentos y recursos destinados a mitigaciones por presencia de nuevas plagas y contaminantes, así como la imposibilidad de ingresar los cargamentos rechazados en los mercados internacionales de destino. Este es el marco, a partir del cual se deberían ampliar y mejorar las capacidades humanas, institucionales y de infraestructura necesarias para responder con más eficacia y rapidez a los nuevos riesgos e innovaciones del sector alimentario; consolidándose la confianza de los consumidores, tanto de los mercados nacionales como externos de toda la región.

\section{ReferenCias bibliograficas}

ARTECONA, Raquel; FLORES, Fernando. Observatorio del control aduanero a las importaciones de Estados Unidos: estándares técnicos. Washington DC: CEPAL, 2009.

BASHAR, Abu; AHMAD, Irshad; WASI, Mohammad. A Study of Influence of Demographic Factors on Consumer Impulse Buying Behavior. Journal of Management Research, v. 13, n. 3, p. 145-154, 2013

BANCO INTERAMERICANO DE DESARROLLO. Guia para la exportación de productos agrícolas y alimentos a la Unión Europea. 2010. Notas Técnicas. 
BOZA, Sofía; FERNÁNDEZ, Felipe. World Trade Organization members' participation in mechanisms under the Sanitary and Phytosanitary Agreement. International Journal of Trade and Global Markets. En prensa.

BUZBY, Jean; UNNEVEHR, Laurian; ROBERTS, Dona. Food Safety and Imports: An Analysis of FDA Food-Related Import Refusal Reports. Economic Information Bulletin 58626, n 39, p. 49. 2008.

DARBY, Michael R.; KARNI, Edi. Free Competition and the Optimal Amount of Fraud. Journal of Law and Economics, v. 16, n. 1, p. 67-88. 1973.

ELDER, David. Ensuring the safety of imported products: consumer updates. 2013.
ORGANIZACIÓN PARA LA AGRICULTURA Y ALIMENTACIÓN. Inocuidad y calidad de los alimentos en Europa: aspectos relacionados con la calidad, el equilibrio nutricional, la importancia de los terrenos agrícolas y el patrimonio cultural ("terroirs"). In: CONFERENCIA REGIONAL DE LA FAO PARA EUROPA, 24., 2004. 2004.

GOVERNMENT ACCOUNTABILITY OFFICE. Food safety: Federal Efforts to Ensure the Safety of Imported Foods are Inconsistent and Unreliable. Report to the Chairman, Permanent Subcommittee on Investigations. Washington DC.: U.S. Senate, 1998. 
Para publicar na Revista de Direito Internacional, acesse o endereço eletrônico www.rdi.uniceub.br ou www.brazilianjournal.org.

Observe as normas de publicação, para facilitar e agilizar o trabalho de edição. 